\title{
PREDICTION OF STRUCTURAL RESPONSE BASED ON GROUND ACCELERATION USING ARTIFICIAL NEURAL NETWORKS
}

\author{
RENI SURYANITA ${ }^{1 *}$, HARNEDI MAIZIR $^{2}$, HENDRA JINGGA ${ }^{3}$ \\ ${ }^{1,3}$ Faculty of Engineering, University of Riau, Pekanbaru, Indonesia \\ ${ }^{2}$ Civil Engineering Department, Sekolah Tinggi Teknologi Pekanbaru, Pekanbaru, Indonesia
}

\section{Keywords:}

Artificial Neural Networks

Ground Acceleration

Mean-Squared Error

Response Spectrum

Structural Response

Received: 21 November 2016

Accepted: 19 January 2017

Published: 15 April 2017

\begin{abstract}
This study utilizes Artificial Neural Network (ANN) to predict structural responses of multi-storey reinforced concrete building based on ground acceleration. The strong ground acceleration might cause catasthropic collapse of multi-storey building which leads to casualties and property damages. Therefore, it is imperative to properly design the multi-storey building against seismic hazard. Seismic-resistant building design process requires structural analysis to be performed to obtain the necessary building responses. Modal response spectrum analysis is performed to simulate ground acceleration and produce structural response data for further use in the ANN. The ANN architecture comprises of 3 layers: an input layer, a hidden layer, and an output layer. Ground acceleration parameters from 34 provinces in Indonesia, soil condition, and building geometry are selected as input parameters, whereas structural responses consisting of acceleration, velocity and displacement (story drift) are selected as output parameters for the ANN. As many as 6345 data sets are used to train the ANN. From the overall data sets, 4590 data sets $(72 \%)$ are used for training process, 877 data sets (14\%) for the validation process, and 878 data sets (14\%) for testing. The trained ANN is capable for predicting structural responses based on ground acceleration at (96\%) rate of prediction and the calculated Mean-Squared Errors (MSE) as low as 1.2.10 ${ }^{-4}$. The high accuracy of structural response prediction can greatly assist the engineer to identify the building condition rapidly and plan the building maintenance routinely.
\end{abstract}

(C)2017 KKG Publications. All rights reserved.

\section{INTRODUCTION}

One of the so many factors that affect the aftermath of earthquake disaster is the resilience of the infrastructure building against the strong ground acceleration. Critical infrastructure building such as hospital, school, power plant office, and governmental buildings are most likely multi-storey buildings which are very prone to seismic loading. During strong ground motion, multi-storey building might collapse in brittle way that endangers its occupants due to the massive dead weight, especially for Reinforced Cement Concrete (RCC) building. Other than that, tall building if not designed properly will experience excessive displacement (storey-drift) that causes discomfort and might damage non-structural components such as partition wall, window, and door which block evacuation passage. Due to these facts, multi-storey building shall be designed properly to exhibit ductile behavior and controlled deformations during strong ground motion.

Story drift is one of the most important limit states in multi-storey building structure design. A building shall not drift excessively to provide better performance and prevent damage to non-structural elements such as walls and doors. Provisions that limit story drift vary depending on which code is used [1], [2], [3]. Frequently, story drift governs the design of structural elements rather than strength.

Finite Element Method (FEM) is currently the best available method to analytically calculate the story drift of multi-storey buildings. Performing FEM for such complex buildings could be very tedious to be hand-calculated if not practically impossible. To help in faster and more accurate calculations, many FEM software programs specialized for Civil Engineering applications are developed and widely available in the market. However, precisely the modelling and running analysis of building structures in FEM software is indeed very time-consuming especially for nonlinear and dynamic analysis. Though Finite Element Method for structural analysis is accurate, it is relatively slow. To provide an adequate early prediction of structural responses such as acceleration, velocity and displacement (story drift) at a faster rate, ANN method may be used.

ANN method is a general prediction tool which is widely used in various fields of application, including Civil Engineering. Artificial Neural Networks are simplified models of the biological nervous system and have drawn their mo-

\footnotetext{
* Corresponding author: Reni Suryanita

†Email: reni.suryanita@eng.unri.ac.id
} 
tivation from the kind of computing performed by a human brain [4]. An Artificial Neural Network is organized into a sequence of layers with full or random connections between the layers. The typical Neural Networks are fully connected, which means there is a connection between each neuron in any given layer to each neuron in the next layer. ANN is capable of modelling the nonlinear relationship between input and output parameters. ANN works by processing weighted input data using certain algorithms to produce a desired output [5]. The relationship between neurons in ANN is represented by weight factors that will be modified through a training process. If sufficient data sets are available and learning algorithm is correctly chosen, the training process will modify the weight factors, by each iteration performed and eventually the desired output will be achieved. Many researchers have studied the application of ANN in multi-storey structure to predict the health of the building, such as [6], [7], [8]. Other studies related to the application of ANN in dynamic structure analysis are the prediction of inelastic response spectra and have been done by [9] and artificial earthquakes and response spectra [10]. The previous study has been done by the author to predict the bridge health condition based on acceleration and displacement data domain [11].

In this study, the ANN is used to predict structural response of reinforced concrete multi-storey building based on ground acceleration in 34 provinces of Indonesia. Indonesia is one of the highest-risk seismic zones in the world, where it is crossed by the Pacific Ring of Fire, which refers to the geographical region with the most active tectonic plate and volcanic activities on earth (for example: Krakatau Volcano). This results in a high tendency of strong ground motion to occur due to earthquake in the Pacific Ring of Fire region. In
2004, a whopping 9.3 Ritcher-scale mega quake struck Aceh on the Western Coast of Sumatera Island, which was then followed by a tsunami that travelled several kilometers inland. In all the aforementioned cases, the property damage was severe and the casualty was huge [12]. The high accuracy of structural response prediction can greatly assist the engineer to identify the building condition rapidly due to earthquake loading and plan the building maintenance routinely.

\section{ARTIFICIAL NEURAL NETWORK}

ANN is a mathematical model inspired by its biological neural network counterpart. The ANN system comprises of several processing layers and neurons. Just like the biological neural network, the connection and signal transfer between neurons and layers enable the ANN system to process the given input signal into appropriate outputs, which is later called prediction. ANN possesses the capability to predict output based on any given input in which the mathematical relationship between the input and output parameter is nonlinear, complex, and often vague. Common multi-layer ANN system comprises of an input layer, hidden layer, and the output layer (Figure 1). Input layer consists of input neurons that receive external signals (input data). Hidden layer also consists of neurons that receive signals from input neurons and transfer it to the output layer. The number of neurons in hidden layer affects the prediction rate and the ability of the ANN system to cope with nonlinear relationship between variables. Finally, output layer consists of output neurons that represent the output parameters to be predicted. The difference between the predicted output value and the target value (the true value according to learning data set) is the error of the ANN system.

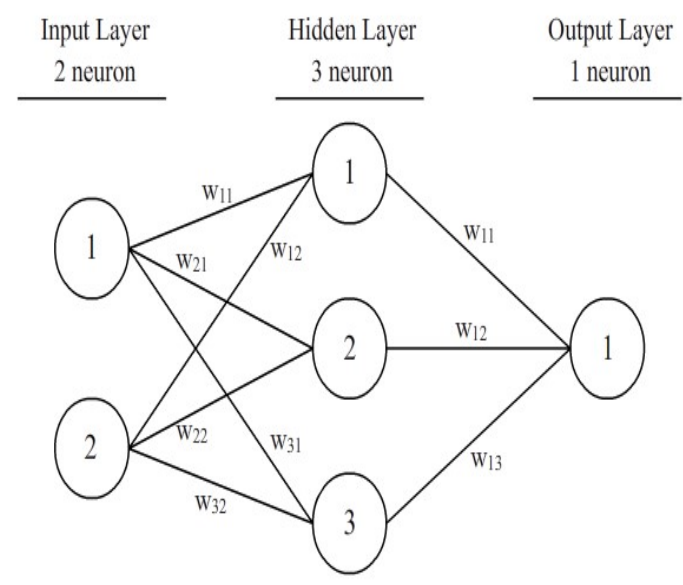

Fig. 1. Simple ANN scheme 
ANN neuron's functionality is analogue to the biological neuron. The synapse strength in biological neural network is represented by the weight factor in the ANN system (for example: notated as w11 in Figure 1). The initial values of the weight factors are usually random, which are later modified through a process called ANN training, iteration, or learning process. The ANN learning process requires a set of data to 'train' the ANN before it is ready for testing. The trained ANN system is expected to possess the capability to predict outputs based on any given inputs at decent accuracy. The commonly adopted criteria to evaluate the performance of the ANN system are Mean-Squared-Error (MSE) and Coefficient of Correlation (R). Backpropagation Artificial Neural Network is one of the most widely used types of ANN.

According to [13], [15], [16], [17] the Backpropagation Neural Network yields better outcomes than other Artificial Intelligence method such as Genetic Algorithm. The Backpropagation ANN algorithm consists of two calculation phases: feed-forward calculation and backpropagation calculation. During the feed-forward calculation, input data are fed into the input layer, then the calculation is continued until it reaches the output layer.

The difference between the predicted output value and the target value is used to calculate the error value. During the backpropagation calculation, the error value obtained in the previous phase is used to modify the weight factors of each neuron in the output layer, then the hidden layer. The completion of one feed-forward and backpropagation calculation for each data set is called one epoch.

The feed-forward calculation uses Equation 1 and 2 to compute the value of the neuron [14].

$$
\begin{aligned}
& \xi_{j}^{l}=\sum_{i=1}^{N_{l-1}} w_{j i}^{l} x_{i}^{l-1} \\
& \sigma_{j}^{l}(\xi)=\frac{1}{1+e^{-\xi_{j}^{l}}}
\end{aligned}
$$

Where: $\xi_{j}^{l}=$ net input of neuron $\mathrm{j}$ at layer $\mathrm{l}$; $w_{j i}^{l}=$ weight factors between neuron $\mathrm{j}$ at layer $\mathrm{l}$ and neuron $\mathrm{i}$ at layer (1 - 1);

$x_{i}^{l-1}=$ value of neuron i at layer $(1-1)$;

$N_{l-1}$ number of neurons in layer (1 - 1); and

$\sigma_{j}^{l}(\xi)=$ sigmoid transfer function to compute the final value of neuron $\mathrm{j}$ at layer 1 .

To evaluate the performance of the ANN system before proceeding to the backpropagation calculation, MSE and Coefficient of Correlation (R) are computed using Equation 3 and 4 , respectively.

$$
M S E=0.5\left(T_{i}-Y_{i}\right)^{2}
$$

$$
R=\frac{n \sum T_{i} Y_{i}-\left(\sum T_{i}\right)\left(\sum Y_{i}\right)}{\sqrt{n\left(\sum T_{i}^{2}\right)-\left(\sum T_{i}^{2}\right)} \sqrt{n\left(\sum Y_{i}^{2}\right)-\left(\sum Y_{i}^{2}\right)}}
$$

Where: $T_{i}=$ target value based on learning data set;

$Y_{i}=$ predicted output value; and

$\mathrm{n}=$ the number of data sets.

\section{METHODOLOGY}

ANN analysis requires an amount of learning data sets to perform the training, validation, and testing process. In this study, the ANN data sets were generated by performing structural analysis on several varieties of building the structure model, soil condition, and seismic location. In the following sub-sections, the methodology used in this research will be described in detail.

\section{Building Structure Model}

The multi-storey building structure models are Reinforced Cement Concrete (RCC) moment frames combined with shear walls. In this research, 3 variations of building height are adopted: 10 storey (Model 1), 15 storey (Model 2), and 20 storey (Model 3), as tabulated in Table 1. The interstorey height is 4.5 meters at base and 4 meters at other stores. The floor plan for all storeys is identical as shown in Figure 2.

TABLE 1

MULTI-STOREY BUILDING STRUCTURE MODELS

\begin{tabular}{llll}
\hline \hline Geometry Parameters & Model 1 & Model 2 & Model 3 \\
\hline Number of bays in X direction & 7 & 7 & 7 \\
Number of bays in Y direction & 6 & 6 & 6 \\
Total floor length in X direction & $42 \mathrm{~m}$ & $42 \mathrm{~m}$ & $42 \mathrm{~m}$ \\
Total floor length in Y direction & $36 \mathrm{~m}$ & $36 \mathrm{~m}$ & $36 \mathrm{~m}$ \\
Number of storeys & 10 & 15 & 20 \\
Total building height & $40.5 \mathrm{~m}$ & $60.5 \mathrm{~m}$ & $80.5 \mathrm{~m}$ \\
\hline \hline
\end{tabular}




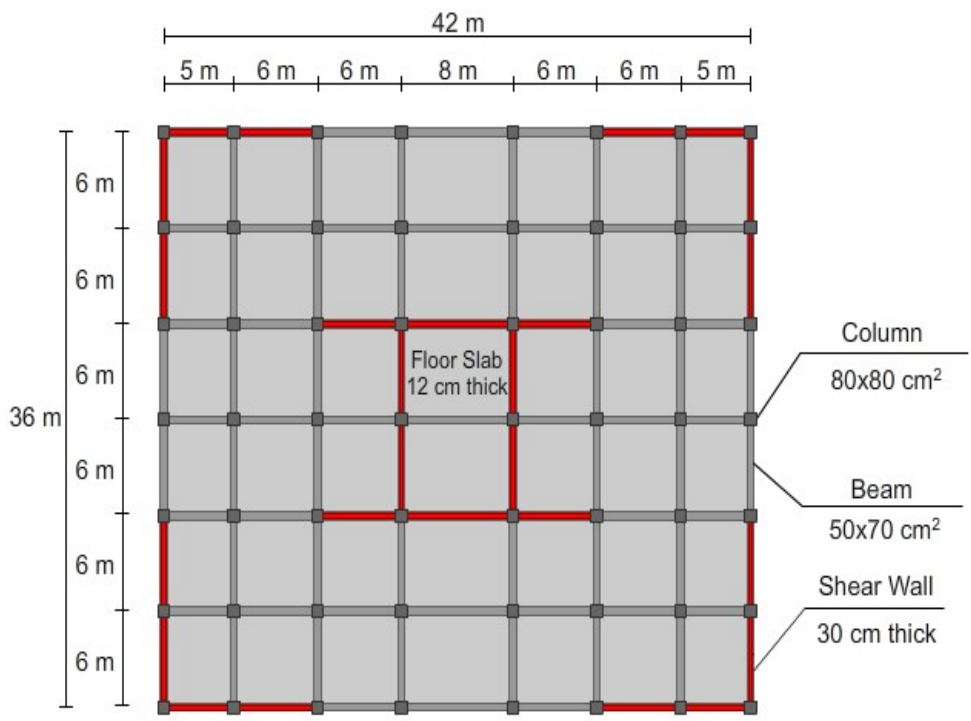

Fig. 2. Floor plan of the multi-storey building

\section{Seismic Analysis: Modal Response Spectrum Analysis}

Modal response spectrum analysis was performed to obtain the responses of the building structure models (storey displacement, velocity, and acceleration). The seismic load was included as seismic response spectrum plot which shows the relationship between the design Structure Acceleration (Sa) and the structure's period of free vibration (T). The Sa vs. T plot varies with soil condition and seismic location. In this study, 34 capital cities and 13 other cities in Indonesia were selected as seismic location with 3 soil conditions (soft, medium, and hard soil). By adopting 47 cities in Indonesia with 3 possible soil conditions, 141 seismic response spectrum plots were obtained. One of the seismic response spectrum plots for Banda Aceh City is shown in Figure 3. For each seismic load, 10 building response data were generated from modal response spectrum analysis from Model 1, 15 data from Model 2, and 20 data from Model 3, which sums up to 45 data. Therefore, as many as 6345 data sets $(141 \mathrm{x} 45)$ were generated from the whole structural analysis process.

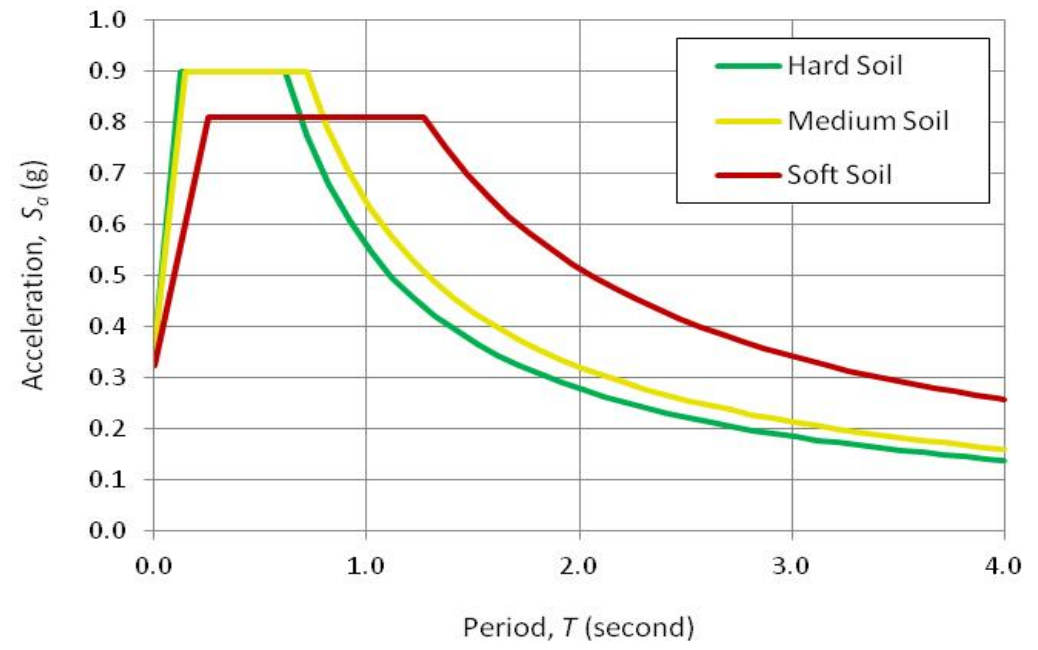

Fig. 3. Seismic response spectrum plot for Banda Aceh city 


\section{Proposed Artificial Neural Network Architecture}

The proposed Backpropagation ANN architecture on the prediction of building structure response due to seismic load in Indonesia is as shown in Figure 4. The ANN architecture consists of 3 layers: input layer with 8 neurons, hidden layer with 24 neurons, and output layer with 6 neurons. The input parameters are Peak Ground Acceleration (PGA), design spectral acceleration at short period $\left(S_{D S}\right)$, design spectral ac- celeration at 1 second of the period $\left(S_{D 1}\right)$, the lower limit of period that results in maximum acceleration $\left(T_{0}\right)$, the upper limit of period that results in maximum acceleration $\left(T_{S}\right)$, soil condition, building total height, and storey elevation (base level was not included). Whereas the output parameters are storey displacement, velocity, and acceleration in both orthogonal horizontal directions ( $\mathrm{X}$ and $\mathrm{Y}$ ).

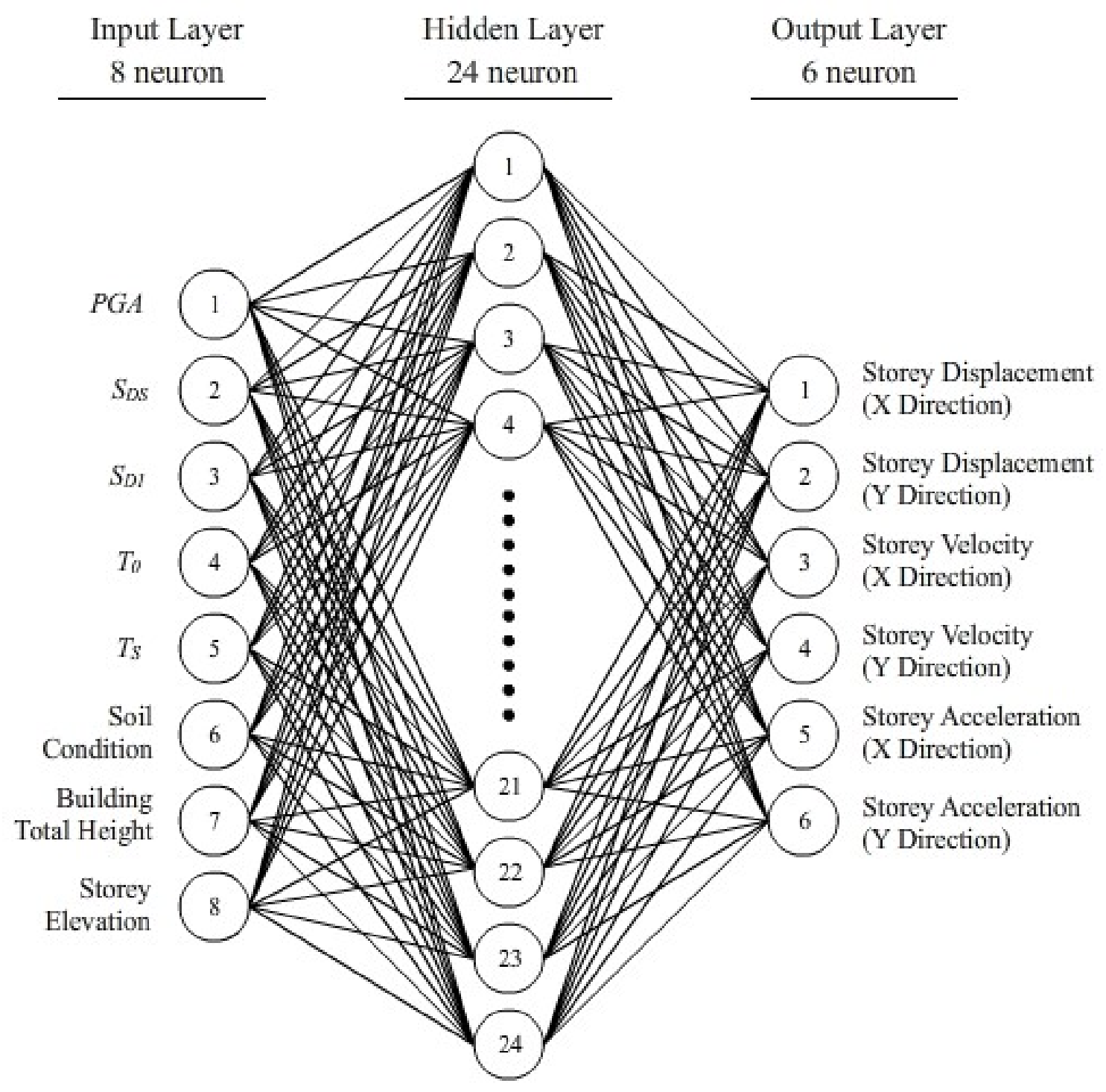

Fig. 4. Proposed backpropagation ANN architecture

\section{Learning Data Sets for the ANN System}

As stated in previous sub-section of this work, as many as 6345 learning data sets are obtained from the structural analysis and these data sets are fed into the ANN system for train- ing, validation, and testing process (Table 2 and Table 3). From the overall data sets, 4590 data sets $(72 \%)$ are used for training process, 877 data sets (14\%) for the validation process, and 878 data sets (14\%) for testing. 
TABLE 2

ANN LEARNING DATA SETS FOR INPUT DATA

\begin{tabular}{lllllllll}
\hline \hline & & \multicolumn{7}{c}{ Input Data } \\
\hline No. & Input 1 & Input 2 & Input 3 & Input 4 & Input 5 & Input 6 & Input 7 & Input 8 \\
& PGA $(\mathrm{g})$ & $S_{D S}(\mathrm{~g})$ & $S D_{1}(\mathrm{~g})$ & $T_{0}(\mathrm{sec})$ & $T_{1}(\mathrm{sec})$ & SoilCond. $^{1}$ & Building Height $(\mathrm{m})^{\text {Elev.(m) }}$ \\
\hline 1. & 0.621 & 0.899 & 0.557 & 0.124 & 0.619 & 0 & 40.5 & 4.5 \\
2. & 0.621 & 0.899 & 0.557 & 0.124 & 0.619 & 0 & 40.5 & 8.5 \\
3. & 0.621 & 0.899 & 0.557 & 0.124 & 0.619 & 0 & 40.5 & 12.5 \\
4. & 0.621 & 0.899 & 0.557 & 0.124 & 0.619 & 0 & 40.5 & 16.5 \\
$\vdots$ & $\vdots$ & $\vdots$ & $\vdots$ & $\vdots$ & $\vdots$ & $\vdots$ & $\vdots$ & $\vdots$ \\
6340. & 0.600 & 0.900 & 0.960 & 0.213 & 1.067 & 2 & 80.5 & 60.5 \\
6341. & 0.600 & 0.900 & 0.960 & 0.213 & 1.067 & 2 & 80.5 & 64.5 \\
6342. & 0.600 & 0.900 & 0.960 & 0.213 & 1.067 & 2 & 80.5 & 72.5 \\
6343. & 0.600 & 0.900 & 0.960 & 0.213 & 1.067 & 2 & 80.5 & 76.5 \\
6344. & 0.600 & 0.900 & 0.960 & 0.213 & 1.067 & 2 & 80.5 & 80.5 \\
6345. & 0.600 & 0.900 & 0.960 & 0.213 & 1.067 & 2 & 80.5 & \\
\hline \hline
\end{tabular}

Note: ${ }^{1}$ Soil condition: $0=$ hard soil, $1=$ medium soil, $2=$ hard soil

\section{RESULTS AND DISCUSSION}

The ANN learning process was conducted by using the following learning parameters:

1. Learning rate $=0.05$

2. Number of epochs (iterations) $=1000$

3. Momentum coefficient $=0$

4. Variable normalization range $=0-0.5$

The learning parameters were selected from several trial values which produce the best prediction performance.

\section{ANN Analysis Computer Program}

The ANN analysis (learning process) was performed using an ANN tool (software) written using VB.NET Language in Visual Studio Community 2015 IDE. The screenshot of the ANN tool's user interface after 1000 epochs of the learning process is shown in Figure 5.

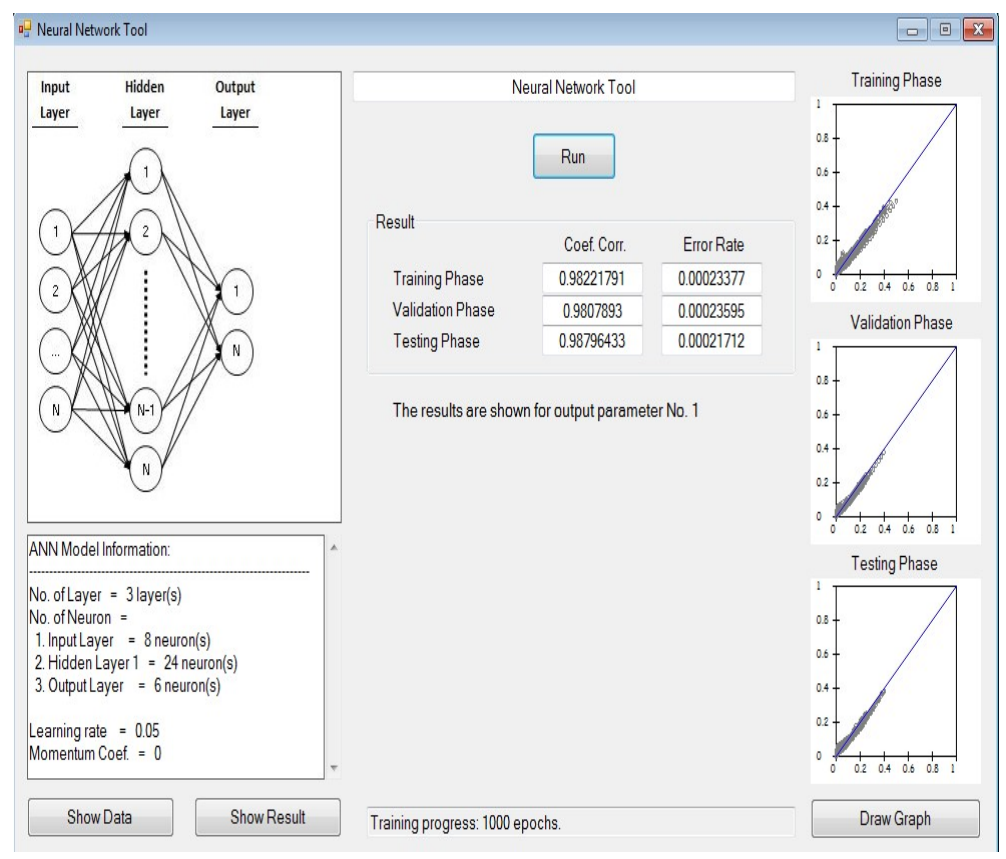

Fig. 5. ANN learning tool screenshot after 1000 epochs 
TABLE 3

ANN LEARNING DATA SETS FOR TARGET DATA

\begin{tabular}{lllllll}
\hline \hline & \multicolumn{5}{c}{ Target Data } \\
\hline No. & Target 1 & Target 2 & Target 3 & Target 4 & Target 5 & Target 6 \\
& Disp. X $(\mathrm{m})$ & Disp. Y $(\mathrm{m})$ & Veloc. X $(\mathrm{m} / \mathrm{sec})$ & Veloc.Y $(\mathrm{m} / \mathrm{sec})$ & Accel. X $\left(\mathrm{m} / \mathrm{sec}^{2}\right)$ & Accel. Y $\left(\mathrm{m} / \mathrm{sec}^{2}\right)$ \\
\hline 1. & 0.0067 & 0.0075 & 0.1262 & 0.1272 & 4.1815 & 3.3948 \\
2. & 0.0146 & 0.0161 & 0.2396 & 0.2469 & 5.7762 & 4.9957 \\
3. & 0.0237 & 0.0260 & 0.3590 & 0.3713 & 6.8525 & 6.1938 \\
4. & 0.0338 & 0.0368 & 0.4831 & 0.4986 & 7.5491 & 6.9656 \\
$\vdots$ & $\vdots$ & $\vdots$ & $\vdots$ & $\vdots$ & $\vdots$ & $\vdots$ \\
6340. & 0.3371 & 0.3573 & 1.6109 & 1.6115 & 6.3718 & 5.9821 \\
6341. & 0.3638 & 0.3854 & 1.7389 & 1.7390 & 6.7544 & 6.3677 \\
6342. & 0.3900 & 0.4130 & 1.8687 & 1.8685 & 7.4165 & 7.0298 \\
6343. & 0.4156 & 0.4399 & 1.9994 & 1.9989 & 8.3694 & 7.9600 \\
6344. & 0.4407 & 0.4662 & 2.1300 & 2.1290 & 9.5280 & 9.0674 \\
6345. & 0.4653 & 0.4920 & 2.2597 & 2.2578 & 10.7557 & 10.2225 \\
\hline \hline
\end{tabular}

\section{Prediction Criteria: MSE and $R$}

The details on the MSE and $\mathrm{R}$ values obtained through the ANN learning process are tabulated in Table 4. After 1000 epochs during the ANN learning process, the MSE was calculated as $2.34 \times 10^{-4}$ for training phase, $2.36 \times 10^{-4}$ for validation phase, and $2.17 \times 10^{-4}$ for testing phase. The Coefficient of Correlation (R) was ranging from 0.899 for acceleration to 0.988 for displacement. This shows that the prediction performance of the trained ANN is sufficiently accurate, which can also be observed on the Target vs. Prediction Plots for all parameters and learning phase (Figure 6).

TABLE 4

MSE AND R DETAILS AFTER ANN LEARNING PROCESS

\begin{tabular}{lllllll}
\hline \hline Parameters & \multicolumn{3}{c}{ Mean-Squared-Error (MSE) } & \multicolumn{2}{c}{ Coefficient of Correlation (R) } \\
\hline & Training & Validation & Testing & Training & Validation & Testing \\
\hline Displacement X & $1.09 \times 10^{-4}$ & $1.01 \times 10^{-4}$ & $1.00 \times 10^{-4}$ & 0.982 & 0.981 & 0.988 \\
Displacement Y & $1.05 \times 10^{-4}$ & $0.96 \times 10^{-4}$ & $0.96 \times 10^{-4}$ & 0.982 & 0.981 & 0.988 \\
Velocity X & $2.05 \times 10^{-4}$ & $2.14 \times 10^{-4}$ & $1.96 \times 10^{-4}$ & 0.972 & 0.964 & 0.982 \\
Velocity Y & $1.99 \times 10^{-4}$ & $1.99 \times 10^{-4}$ & $1.88 \times 10^{-4}$ & 0.972 & 0.965 & 0.983 \\
Acceleration X & $4.04 \times 10^{-4}$ & $4.13 \times 10^{-4}$ & $3.80 \times 10^{-4}$ & 0.928 & 0.901 & 0.957 \\
Acceleration Y & $3.80 \times 10^{-4}$ & $3.93 \times 10^{-4}$ & $3.43 \times 10^{-4}$ & 0.928 & 0.899 & 0.959 \\
Average & $2.34 \times 10^{-4}$ & $2.36 \times 10^{-4}$ & $2.17 \times 10^{-4}$ & 0.961 & 0.949 & 0.976 \\
\hline \hline
\end{tabular}

The trained ANN model achieved in this work is only adequately accurate to predict the structural responses (displacement, velocity, and acceleration) of the building model as described in the Methodology Section of this paper. For different building structure model (framing system, structural element size, floor plan, etc), another ANN model needs to be developed and trained to be compatible with the building behaviour. In further studies, another building's geometry parameters could be added as input parameters in the ANN model such as number of bay, span of bay, building height, etc, so the trained ANN model will be suitable to predict the structural responses of broader variation of building geometry. 
Training Phase

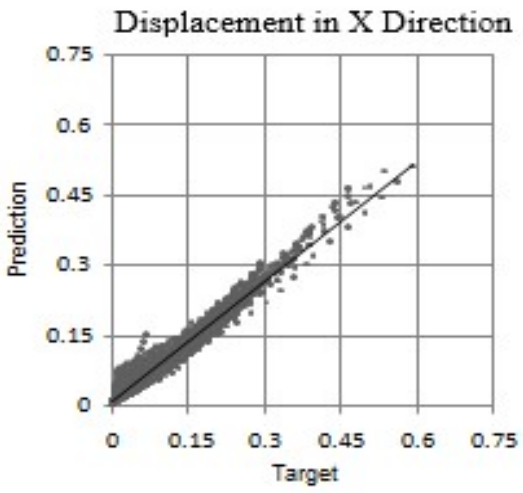

Displacement in Y Direction

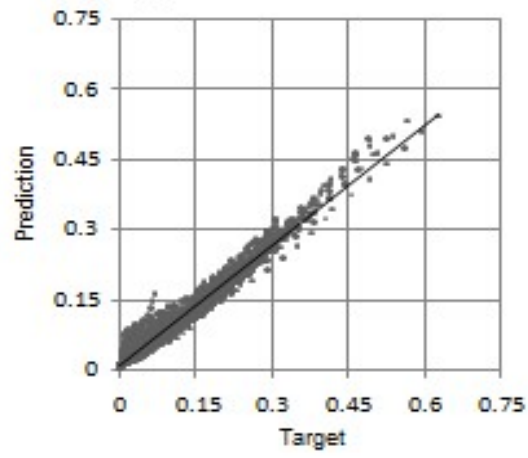

Velocity in X Direction
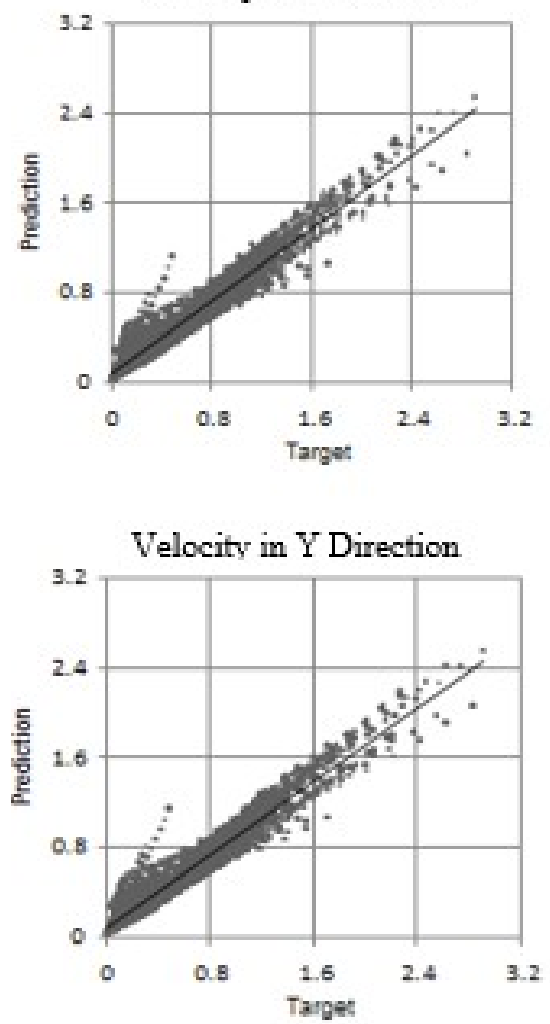

Validation Phase

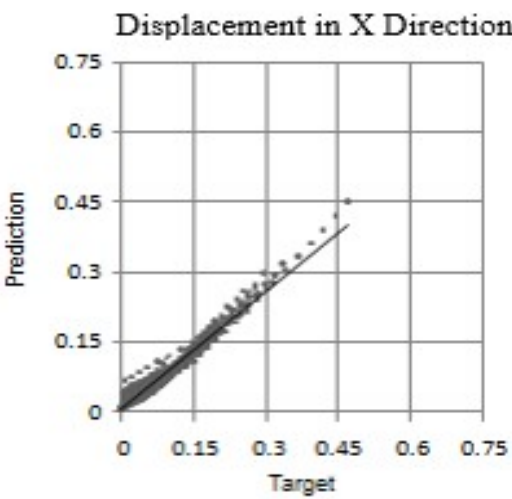

Displacement in Y Direction

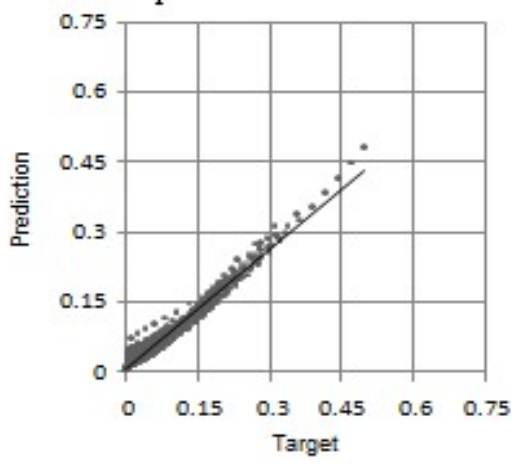

Velocity in $\mathrm{X}$ Direction
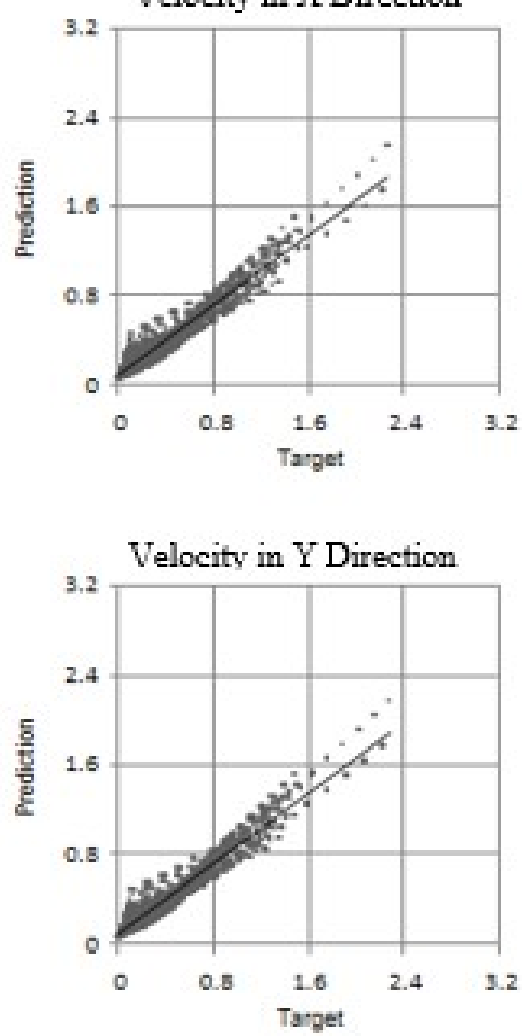

Testing Phase

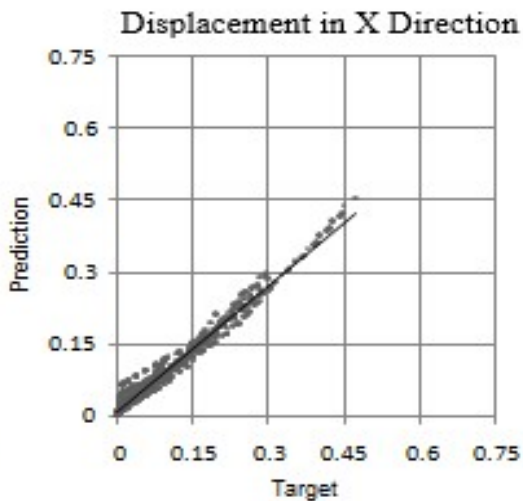

Displacement in Y Direction

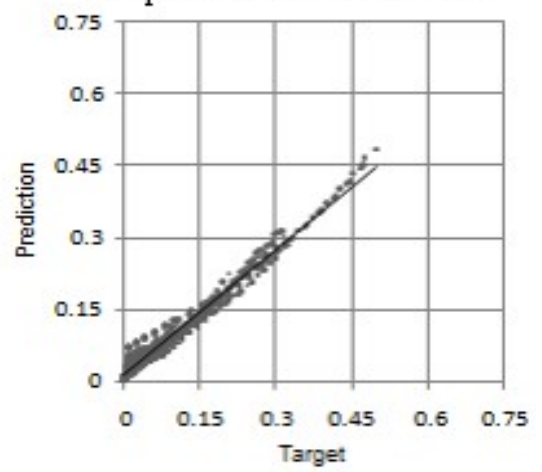

Velocity in X Direction
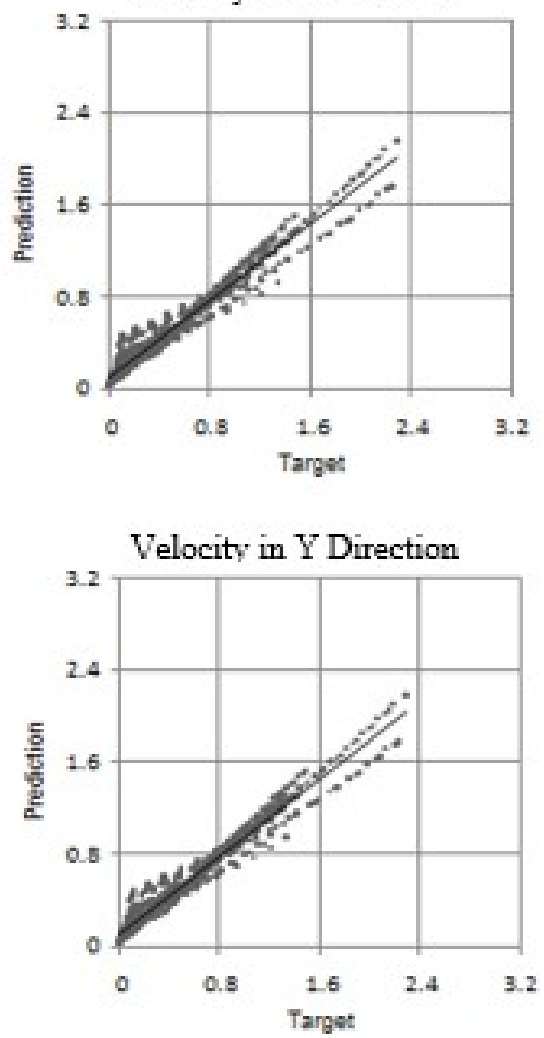

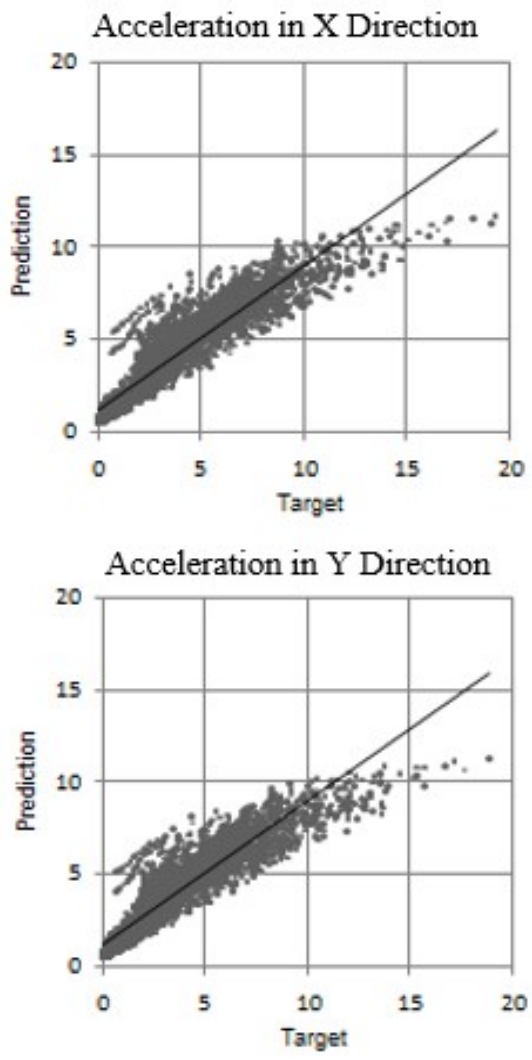
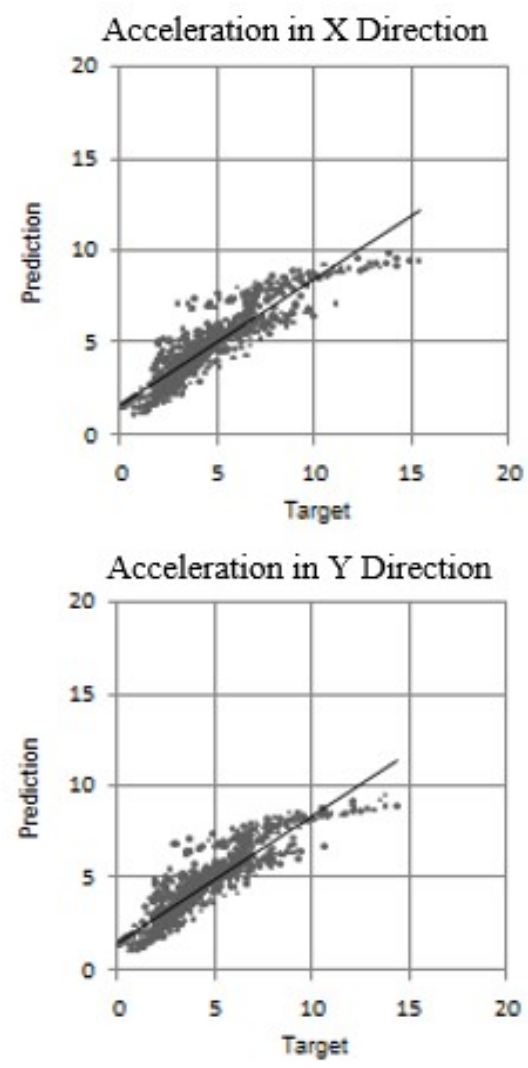
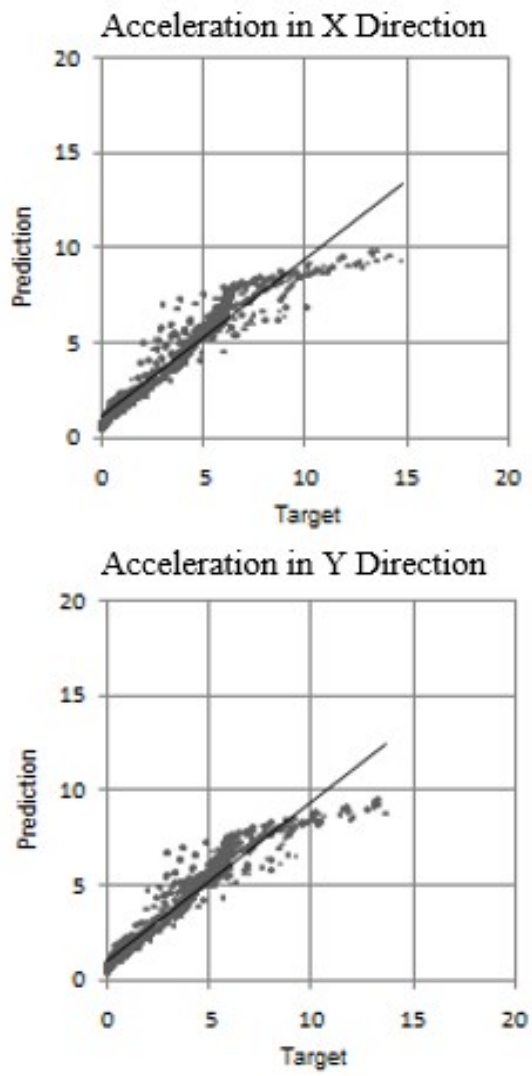

Fig. 6. Target vs. prediction plots after ANN learning process

\section{CONCLUSION}

1. The MSE was calculated as $2.34 \times 10^{-4}$ for training phase, $2.36 \times 10^{-4}$ for validation phase, and $2.17 \times 10^{-4}$ for testing phase.

2. The Coefficient of Correlation ( $\mathrm{R}$ ) was ranging from 0.899 for acceleration to 0.988 for displacement.
3. Both calculated MSE and R values indicate that the prediction performance of the trained ANN is sufficiently accurate.

4. The ANN is a very promising tool to provide an early prediction on structural response such as storey-drift (displacement), velocity and acceleration at multi-storey building in the region of Indonesia to assist further FEM analysis.

\section{REFERENCES}

[1] F. FEMA, "273: NEHRP Guidelines for the seismic rehabilitation of buildings," Federal Emergency Management Agency, Washington, DC, 1997.

[2] B. S. National, "Planning standards for earthquake resistance building structure," Building Seismic Safety Council, Washigton, DC, Rep. SNI 03-1726, 2002.

[3] C. Yang, "Study on Indonesian seismic code SNI 03-1726-2002 and seismic impact to high-rise buildings in Jakarta, Indonesia," in Proceedings of World Academy of Science: Engineering and Technology, 2009.

[4] S. Rajasekaran and G. A. V. Pai, Neural Network, Fuzzy logic, and Genetic Algorithms Syntesis and Applications. New Delhi, India: Prentice Hall, 2007.

[5] V. S. Kanwar, R. P. Singh, N. Kwatra and P. Aggarwal, "Monitoring of RCC structures affected by earthquakes," Geomatics, Natural Hazards and Risk, vol. 7, no. 1, pp. 37-64, 2016.

[6] D. M. Sahoo, A. Das and S. Chakraverty, "Interval data-based system identification of multistorey shear buildings by artificial neural network modelling," Architectural Science Review, vol. 58, no. 3, pp. 244-254, 2015.

[7] M. Vafaei, A. B. Adnan and A. B. Abd. Rahman, "Real-time seismic damage detection of concrete shear walls using artificial neural networks," Journal of Earthquake Engineering, vol. 17, no. 1, pp. 137-154, 2013. 
[8] M. Mardiyono, R. Suryanita and A. Adnan, "Intelligent monitoring system on prediction of building damage index using neural-network," Telecommunication Computing Electronics and Control, vol. 10, no. 1, pp. 155-164, 2012.

[9] E. Bojorquez, J. Bojorquez, S. E. Ruiz and A. Reyes-Salazar, "Prediction of inelastic response spectra using artificial neural networks," Mathematical Problems in Engineering, vol. 2012, pp. 1-15, 2012.

[10] S. C. Lee and S. W. Han, "Neural-network-based models for generating artificial earthquakes and response spectra," Computers \& Structures, vol. 80, no. 20, pp. 1627-1638, 2002.

[11] R. Suryanita and A. Adnan, "Application of neural networks in bridge health prediction based on acceleration and displacement data domain," in Proceedings of the International Multi Conference of Engineers and Computer Scientists, Hong Kong, China, March 13-15, 2013.

[12] T. Lay, H. Kanamori, C. J. Ammon, M. Nettles, S. N. Ward, R. C. Aster and R. Butler, "The great Sumatra-Andaman earth quake of 26 december 2004," Science vol. 308, no. 5725, pp. 1127-1133, 2005.

[13] Z. G. Che, T. A. Chiang and Z. H. Che, "Feed-forward neural networks training: A comparison between genetic algorithm and back-propagation learning algorithm," International Journal of Innovative Computing, Information and Control, vol. 7, no. 10, pp. 5839-5850, 2011.

[14] I. A. Basheer and M. Hajmeer, "Artificial neural networks: Fundamentals, computing, design, and application," Journal of Microbiological Methods, vol. 43, no. 1, pp. 3-31, 2000.

[15] N. A. Zainuddin, I. Norhuda, I. S. Adeib, A. N. Mustapa and S. H. Sarijo, "Artificial neural network modeling ginger rhizome extracted using rapid expansion Super-Critical Solution (RESS) Method," Journal of Advances in Technology and Engineering Research, vol. 1, no. 1, pp. 1-14, 2015.

[16] N. Z. Tawfeeq Abdulnabi and O. Altun, "Batch size for training convolutional neural networks for sentence classification," Journal of Advances in Technology and Engineering Studies, vol. 2, no. 5, pp. 156-163, 2016.

[17] H. Maizir, R. Suryanita and H. Jingga, "Estimation of pile bearing capacity of single driven pile in sandy soil using finite element and artificial neural network methods," International Journal of Applied and Physical Sciences, vol. 2, no. 2, pp. 45-50, 2016.

— This article does not have any appendix. - 